\title{
Phase Transition of $\mathrm{La}_{0.62} \mathrm{Sr}_{0.38} \mathrm{MnO}_{3}$ Perovskite Manganites
}

\author{
K. Sakthipandi ${ }^{a,}{ }^{*}$ and M. Selvam ${ }^{b}$ \\ a Department of Physics, Sethu Institute of Technology. Kariapatti 626 115, Tamil Nadu, India \\ b Centre for Nano Science and Technology, K S Rangasamy College of Technology, Tiruchengode 637215, Tamil Nadu, India
}

*Corresponding Author sakthipandi@gmail.com (Sakthipandi K)

Received : $1^{\text {st }}$ March 2019 Accepted : $5^{\text {th }}$ April 2019

\begin{abstract}
Bulk and nano $\mathrm{La}_{0.62} \mathrm{Sr}_{0.38} \mathrm{MnO}_{3}$ perovskite manganite samples were prepared using solid state and sonochemical reaction respectively. The ultrasonic velocities measurement was made on prepared samples using ultrasonic through transmission method, at a fundamental frequency of $5 \mathrm{MHz}$ over wide range of temperatures. The temperature dependence of the ultrasonic parameters shows an interesting anomaly in bulk and nano perovskite samples. The observed dramatic softening and hardening in sound velocities are related to phase transitions. Further, a decrease in grain size in the nanostructured sample leads to a shift in the ferromagnetic transition temperature $\left(\mathrm{T}_{\mathrm{C}}\right)$ from 375 to $370 \mathrm{~K}$.
\end{abstract}

Keywords: Perovskite, Ultrasonic velocity, Grain size, Curie temperature

\section{Introduction}

In the past few years, perovskite manganites $R_{1 \sim}$ ${ }_{x} \mathrm{~A}_{\mathrm{x}} \mathrm{MnO}_{3}$ (where $\mathrm{R}$ trivalent rare earth elements and $\mathrm{A}$ divalent alkaline earth ions) were attracted for potential applications like solid oxide fuel cells, magnetic sensors/reading heads and frequency switching devices due to their unique physico chemical [1-3], and giant magneto resistance (GMR) properties [4]. In perovskite magnetic materials, particularly $\mathrm{La}_{0.68} \mathrm{Sr}_{0.32} \mathrm{MnO}_{3}$ (LSMO) perovskite, the existence of highest value of Curie temperature $\left(\mathrm{T}_{\mathrm{C}}\right)$ and very low carrier density with a high spin polarisation of charge carriers make them very promising candidate for room temperature applications. The nanostructured materials are used to widen the opportunities to improve the catalytic activity in solid fuel cells [3]. Generally, the properties of the doped perovskite materials depend on (i) doping concentration $(x)$ [5], (ii) ionic size of A site divalent cation [6], (iii) the variation of doped ions and potential fluctuations between $\mathrm{R}^{3+}$ and $\mathrm{A}^{2+}$ [7] and (iv) phase separation [8]. Therefore, in the present investigation, an attempt has been made to prepare bulk and nanocrystalline LSMO perovskite magnetic materials and to study the structural and phase transitions employing on line ultrasonic velocity measurements.

\section{Experimental procedure}

Bulk and nano $\mathrm{La}_{0.68} \mathrm{Sr}_{0.32} \mathrm{MnO}_{3}$ perovskite manganites were prepared employing respectively solid state and sonochemical reaction methods. The characterisation of prepared samples was made by studies such as X-ray diffraction (XRD), Transmission electron microscope (TEM) and on line ultrasonic measurements $[4,9]$.

\section{Result and Discussion}

The XRD patterns of bulk and nano LSMO perovskite samples are shown in Fig 1 . It is inferred that the observed XRD patterns of the bulk sample reveals the existence of mixed crystalline nature namely rhombohedral and tetragonal crystalline phases. The peaks observed at $27.616^{\circ}$ and $48.365^{\circ}$ correspond to tetragonal phase and other peaks correspond to rhombohedra phase (JCPDS file no.: 89 4461 and 51-0118). On the other hand, rhombohedra phase with the space group of R3c along with the hexagonal structure (JCPDS file no.: 51-0409) is observed in the nano LSMO perovskite. The TEM images of bulk and nano samples are shown in Fig 2. Interestingly, bulk LSMO perovskite samples have sphere like morphology, whereas nano LSMO perovskite samples have honeycomb structure consisting of agglomerated nanoparticles with particle sizes ranging from 30 to $50 \mathrm{~nm}$. The estimated

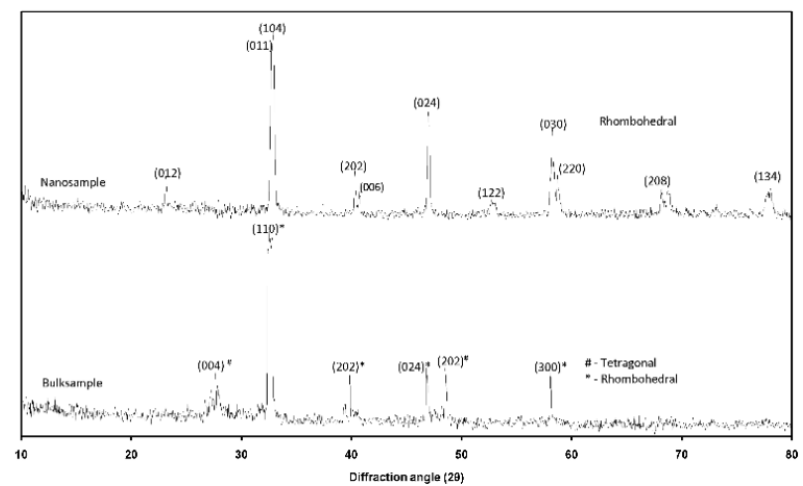

Fig. 1. XRD pattern of a) bulk and b) nano LSMO perovskites 


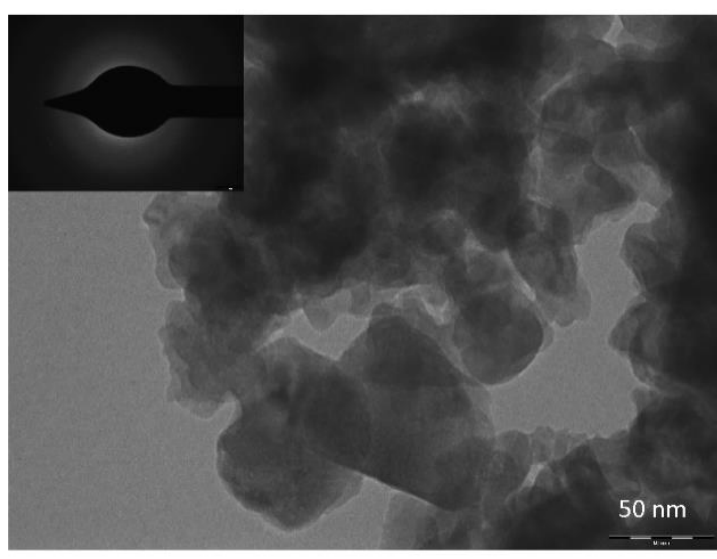

Bulksample

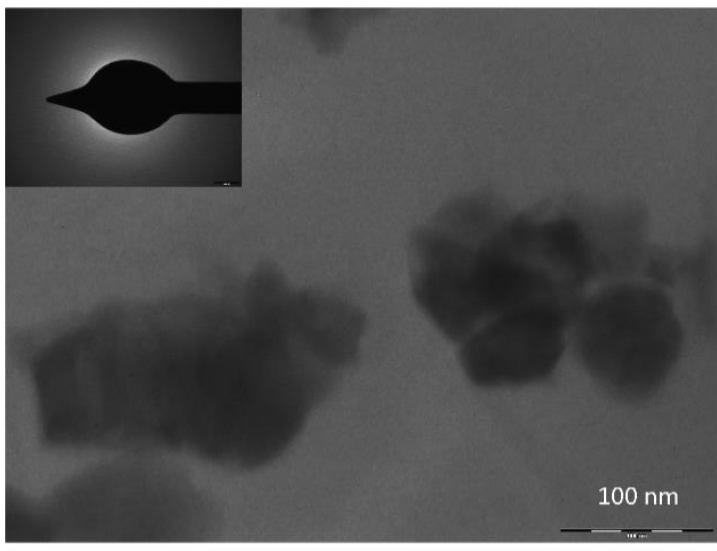

Nanosample

Fig. 2. TEM patterns of a) bulk and b) nano LSMO perovskites

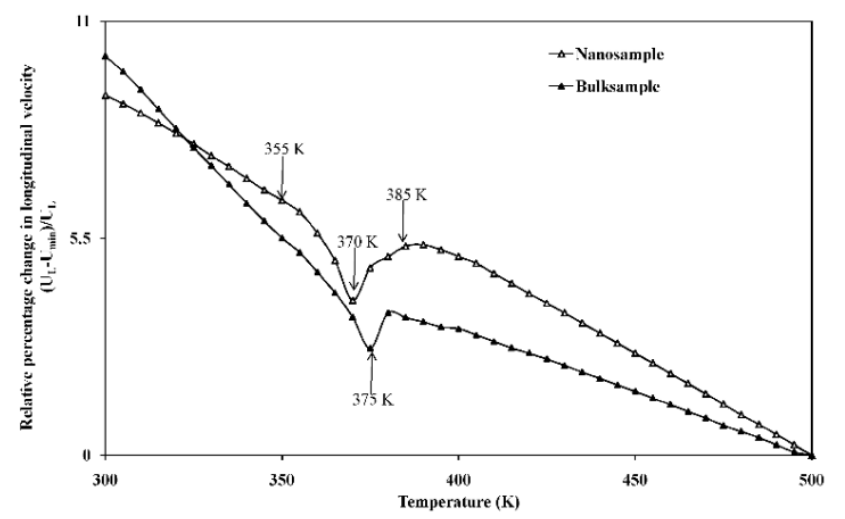

Fig. 3. Temperature dependent relative change in longitudinal velocity of bulk and nano samples

particle size from TEM studies is around $500 \mathrm{~nm}$ for bulk and $50 \mathrm{~nm}$ for nano LSMO perovskite. The temperature dependence of percentage variation in longitudinal $\left(\mathrm{U}_{\mathrm{L}}\right)$ and shear $\left(U_{S}\right)$ velocities of bulk and nano sample are represented respectively in Fig 3. A gradual decrease in velocity and an increase in attenuation are observed in the temperature range 300 to $370 \mathrm{~K}$ and 380 to $500 \mathrm{~K}$ as observed in other solid material [4]. An anomalous behaviour is noticed at 375 $\mathrm{K}$ for bulk sample. The observed sharp dip in velocity and a peak in attenuation at $375 \mathrm{~K}$ in bulk sample is the Curie

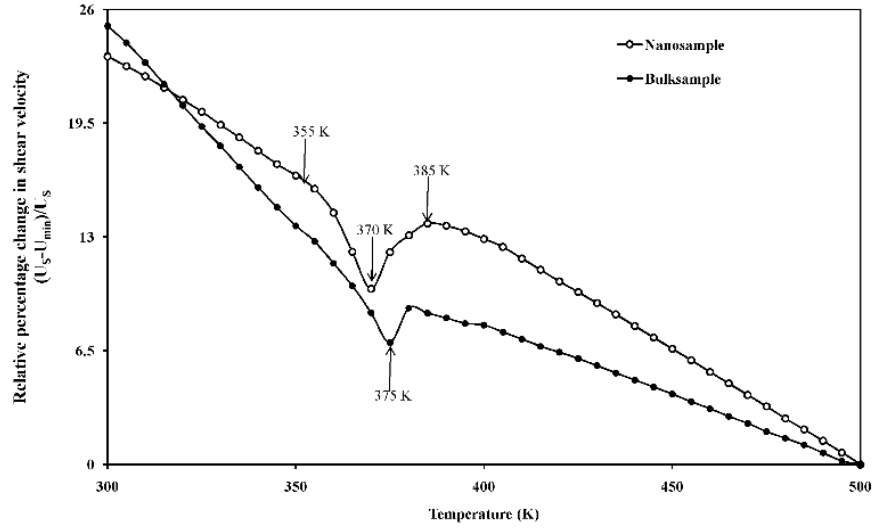

Fig. 4. Temperature dependent relative change in shear velocity of bulk and nano samples

Temperature $\left(\mathrm{T}_{\mathrm{C}}\right)$ of LSMO perovskite wherein a transition from ferromagnetic to paramagnetic takes place $[4,10]$. In nano samples, an initial monotonic decrease in velocities and an increase in attenuation are observed in the temperature range from 300 to $355 \mathrm{~K}$.

Nevertheless, it is interesting to note an anomalous behaviour in the variation of velocities and attenuation in the temperature range from 355 to $385 \mathrm{~K}$. A sharp fall in velocities and a sharp increase in attenuation start at $355 \mathrm{~K}$ and reach the maxima/minima in their variation at $370 \mathrm{~K}$. A further increase in temperature beyond $370 \mathrm{~K}$ leads to a sharp rise in velocities and a sharp decrease in attenuation up to $385 \mathrm{~K}$. Beyond $385 \mathrm{~K}$, a monotonic decrease in velocities and an increase in attenuations are noticed. The shift in the peak from 375 to $370 \mathrm{~K}$ indicates that the $\mathrm{T}_{\mathrm{C}}$ for the perovskite materials is shifted towards the lower value due to the decrease in grain size. Further, the observed broad variation in velocity at $T_{C}$ in nano sample than the bulk sample conforms the absence of sharp FM to PMM transition, as reported [4, 11]. The linear magnetostriction effect is more dominate in LSMO perovskite than volume magnetostriction effect which is evident from larger variation in both velocities $\left(\mathrm{U}_{\mathrm{L}}\right.$ and $\left.\mathrm{U}_{\mathrm{S}}\right)$.

\section{Reference}

[1] G. Lalitha, D. Das, D. Bahadur and P. Venugopal Reddy, Elastic behavior of $\mathrm{La}_{0}{ }_{67} \mathrm{Ca}_{0.33} \mathrm{MnO}_{3}: \mathrm{ZrO}_{2}$ composites, $J$ Alloy Compd. 464 (2008) 6-8.

[2] W. J. Li, Bo Zhang and W. Lu, Structural properties and Raman spectroscopy of $\mathrm{La}(2+4 \mathrm{x}) / 3 \mathrm{Sr}(1-4 \mathrm{x}) / 3 \mathrm{Mn}_{1-}$ ${ }_{\mathrm{x}} \mathrm{Cu}_{\mathrm{x}} \mathrm{O}_{3}(0 \leqslant \mathrm{x} \leqslant 0.2)$, Phys Lett A. 362 (2007) 327-330.

[3] P.Sarkar, P. Mandal, A.K. Bera, S.M. Yusuf, L.S. Sharath Chandra and V. Ganesan, Field induced first -order to second-order magnetic phase transition in $\mathrm{Sm}_{0.52} \mathrm{Sr}_{0.48} \mathrm{MnO}_{3}$, Phys. Rev. B. 78 (2008) 012415.

[4] S. Sankarrajan, K. Sakthipandi and V. Rajendran, Temperature dependent sound velocities, attenuation and elastic moduli anomalies in $\mathrm{Pr}_{1-\mathrm{x}} \mathrm{Sr}_{\mathrm{x}} \mathrm{MnO}_{3}$ perovskite 
manganite materials at $0.28 \leq \mathrm{X} \leq 0.41$, PHASE TRANSIT. 85 (2012) 427-443.

[5] A. Urushibara, Y. Moritomo, T. Arima, A. Asamitsu, G. Kido and Y. Tokura, Insulator metal transition and giant magnetoresistance in $\mathrm{La}_{1 \sim \mathrm{x}} \mathrm{Sr}_{\mathrm{x}} \mathrm{MnO}_{3}$, Phys. Rev. B, 51, (1995) 14103.

[6] H.Y. Hwang, S.W. Cheong, P.G. Radaelli, M. Marezio and B. Batlog, Lattice Effects on the magnetoresistance in doped $\mathrm{LaMnO}_{3}$, Phy. Rev. Lett. 75 (1995) 914.

[7] M. Lide, J. Rodriguez Martinez and J. Paul Attfield, Cation disorder and size effects in magnetoresistive manganese oxide perovskites, Phys. Rev.B, 54 (1996) R15622.

[8] M. Uehara, S. Mori, C.H. Chen and S.W. Cheong, Percolative phase separation underlies colossal magnetoresistance in mixed valant manganites, Nature, 399 (1999) 560-563.

[9] M. Arunachalam, P. Thamilmaran, S. Sankarrajan, and K. Sakthipandi, Study of high temperature metal insulator phase transition in $\mathrm{La}_{1-\mathrm{x}} \mathrm{Ca}_{\mathrm{x}} \mathrm{MnO}_{3}$ employing in situ ultrasonic studies, Physica B: Condensed Matter, 456 (2015) 118-124.

[10]K. Sakthipandi and V. Rajendran, On line phase transitions of bulk and nanocrystalline $\mathrm{La}_{1-}{ }_{\mathrm{x}} \mathrm{Pb}_{\mathrm{x}} \mathrm{MnO}_{3}$ $(\mathrm{x}=0.3,0.4$, and 0.5$)$ perovskite manganite materials using ultrasonic measurements, Mater. Chem. Phys. 138 (2013) 581-592.

[11]R.K. Zheng, C.F. Shu, J.Q. Xie, R.X. Huang and X.G. Li, Charge transport and ultrasonic properties in $\mathrm{La}_{0.57} \mathrm{Ca}_{0.43} \mathrm{MnO}_{3}$ perovskites, Mater. Chem. Phys. 75 (2002) 121-124.

\section{About The License}

(C) 2019 The Authors. This work is licensed under a Creative Commons Attribution 4.0 International License which permits unrestricted use, provided the original author and source are credited. 